\title{
Digitalized Financial Inclusion: A Cause of Development in India
}

\section{Anchit Jhamb ${ }^{1}$ and Swati Aggarwal ${ }^{2 *}$}

${ }^{1}$ University School of Business, Chandigarh University, Punjab, India

${ }^{2}$ University School of Business, Chandigarh University, Himachal Pradesh, India

Keywords: Digitalization; Communication; Society; Government; Youth

\section{Objectives of the Study}

I. To understand the usage of mobiles and internet in the rural and remote areas.

II. To know the financial services available to Indian Population and Digitalized form.

III. To compare both the above options and to find out the results to support the topic.

\section{Introduction}

With the bold steps taken by Honourable Prime Minister of India Sh. Narender Modi ji, Indian developments are taking up new heights and with improved relationships with international neighbours. India has been showing its presence at world stage. The policies are streamlined by the Indian government in such a way that not only the rich high class population instead even the last person in the economy can have access to the policies. There have been few hurdles such as remote locations, cultures, community and class diversification, etc. in the way for the government to reach the grass roots of the economy. Further it becomes really difficult for the Government to reach the lower sections of the society because of the discrepancy in the availability of elementary education due to which there is lack of awareness amongst them. To overcome this hurdle government has tried its best that the communication networks mainly the mobile phone networks and internet are easily available in the manner that the mobile operators are almost covering every inch of the land and trying to cover maximum population of the country and above all it is the market which has driven the intense competition and forcing the companies of all sectors especially the mobile operators to cover the even the last person of the economy. This has helped the Indian customers to get streamlined through one of the electronic communication facility. The availability of internet facility and mobile phones in the remote area as well the Prime Minister of India gave a charge to DIGITILIZATION of India supporting the idea of cashless economy but that's the road ahead for the present time digitalized financial inclusion seems to be attainable and hence the Prime Minister hit the red hot iron very hard and keeping an eye over the youth and its development the digitalization seems very easy.

\section{Nine Pillars of Digital India}

According to the following data released by the TRAI (Telecom Regulation Authority of India) it can stated that India is developing very fast in electronic communication field and Digitalization will one of the major cause of financial inclusion [1].

\section{Digital Financial Services and Financial Inclusion}

According to RBI "Mobile Banking in India Perhaps the biggest change in banking in recent times has been the introduction of mobile banking [2]. The RBI issued its first set of regulatory guidelines to do with mobile banking in 2008, where banks were permitted to transfer funds from one bank account to another through the mobile platform. From 2010 to 2012, the number of users of mobile banking services grew $277.68 \%$ (from 5.96 million to 22.51 million) and the value grew a whopping $875.6 \%$ (from Rs. 6.14 billion to Rs. 59.90 billion) [3]. These figures clearly indicate that mobile banking in the country is growing at a very high rate. Yet, as of 2014, there were 350 to 500 million unique mobile subscribers and only 22 million mobile banking customers (Figure 1). The RBI clearly recognized the potential for a widespread increase in mobile banking as well as the opportunity of increasing financial inclusion in the country, and made recommendations for "addressing the consumer acquisition challenges as well as the technical aspects". Recommendations such as alternate channels for mobile registration such as ATMs, uniformity in the mobile registration process across banks, and standardization and simplification of the MPIN generation process were made by the RBI [4]." And with addition to its AADHAR CARD issuance and linking it with mobile phone was an appreciable move by the Prime Minister making clear, true and transparent information about the population of India and their lifestyle so whole in whole it is an excellent step taken up the government of India. The individual can name a financial service and it is available in the digital form and due to the customer satisfaction criteria taken up the private as well as public sector it is very easy for a customer as now the company reaches the customers. Following is the table showing the fragmented Digital Financial Services market and Examples of some providers [5].

The following table studies the network operators in India and their subscription percentage.

\section{Analysis and Findings from Tables 1 and 2, and Figure 2 and to Support the Topic}

I. From Table 1 it is very clear that there has been a rise in the

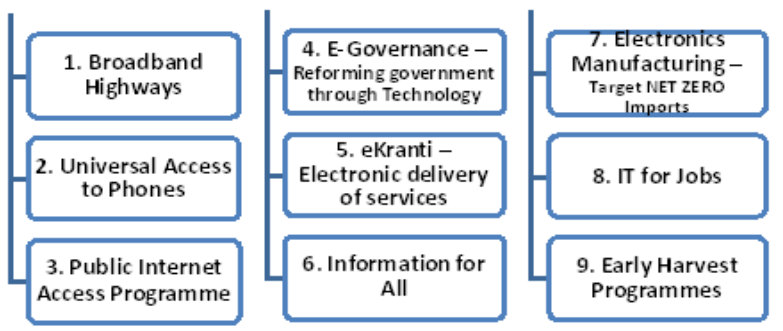

Figure 1: Nine pillars of digital India: Data released by the TRAI (Telecom Regulation Authority of India).

*Corresponding author: Aggarwal S, University School of Business, Chandigarh University, Himachal Pradesh, India, Tel: + 8054381316; E-mail: swati.aggarwal005@gmail.com

Received December 22, 2017; Accepted January 30, 2018; Published February 06, 2018

Citation: Jhamb A, Aggarwal S (2018) Digitalized Financial Inclusion: A Cause of Development in India. Bus Eco J 9: 338. doi: 10.4172/2151-6219.1000338

Copyright: $\odot 2018$ Jhamb A, et al. This is an open-access article distributed under the terms of the Creative Commons Attribution License, which permits unrestricted use, distribution, and reproduction in any medium, provided the original author and source are credited. 
Citation: Jhamb A, Aggarwal S (2018) Digitalized Financial Inclusion: A Cause of Development in India. Bus Eco J 9: 338. doi: 10.4172/21516219.1000338

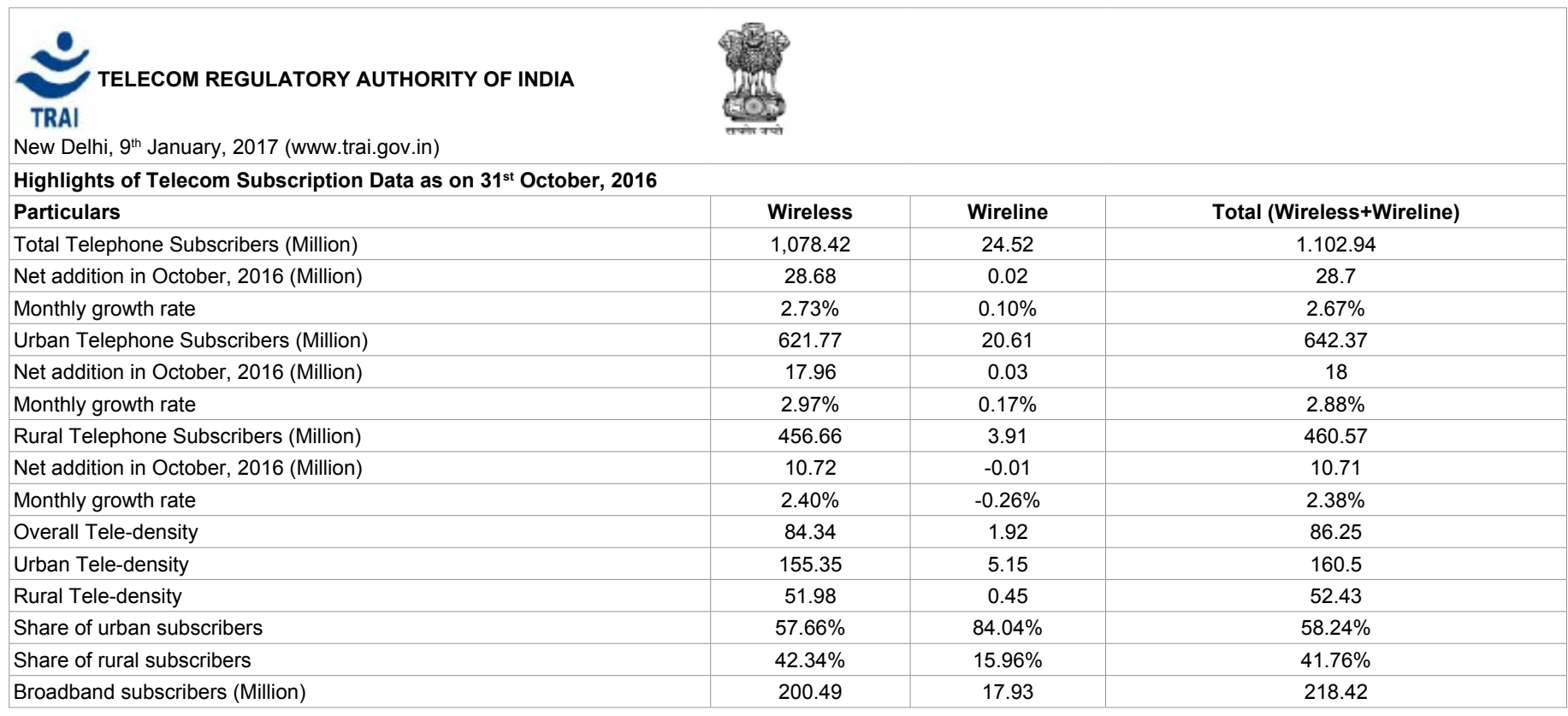

Table 1: Data from TRAI for mobile phone users in India.

\begin{tabular}{|c|c|c|c|c|c|}
\hline \multicolumn{6}{|c|}{ Group company wise \% market share (subscribers) - April 2017} \\
\hline SI.No & Name of Company & Total Sub Figures & Additions in Apr 2017 & $\%$ Market Share & $\%$ Growth over previous month \\
\hline 1 & Bharti Airtel & $27,65,01,427$ & $28,53,044$ & $29.59 \%$ & $1.03 \%$ \\
\hline 2 & Vodafone & $20,98,19,503$ & $7,56,637$ & $22.45 \%$ & $0.36 \%$ \\
\hline 3 & Idea & $19,60,52,705$ & $6,83,858$ & $20.98 \%$ & $0.35 \%$ \\
\hline 4 & Aircel & $9,05,60,441$ & $-3,39,427$ & $9.69 \%$ & $-0.37 \%$ \\
\hline 5 & Telenor & $4,93,44,153$ & $-11,48,996$ & $5.28 \%$ & $-2.33 \%$ \\
\hline 6 & MTNL & $36,25,183$ & $-2,137$ & $0.39 \%$ & $-0.06 \%$ \\
\hline 7 & Rjio & $10,86,80,772$ & 0 & $11.63 \%$ & $0.00 \%$ \\
\hline Total & All India & $93,45,84,184$ & $28,02,979$ & & $0.30 \%$ \\
\hline
\end{tabular}

Table 2: The network operators in India and their subscription percentage.

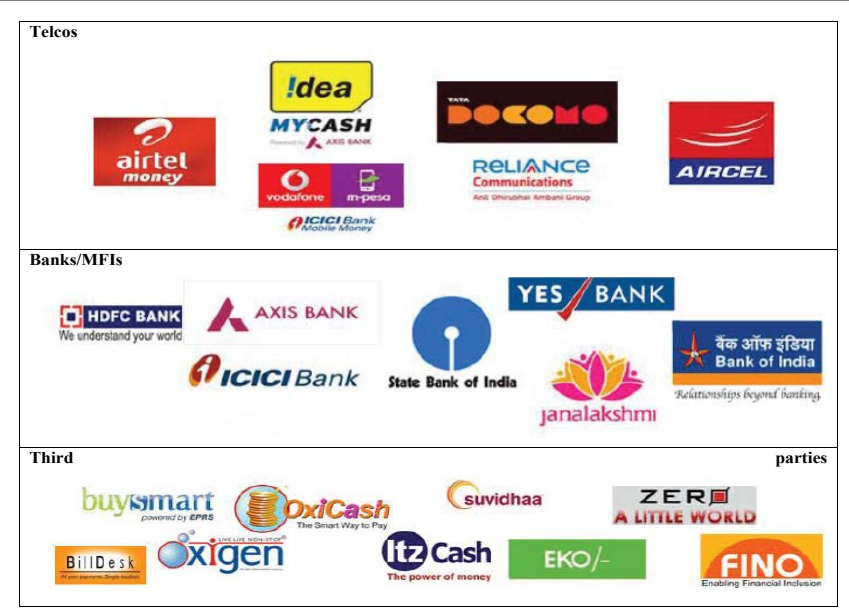

Figure 2: A fragmented Digital Financial Services market and examples of some providers. usage of mobile in the rural area is increasing at a good rate.

II. With the introduction of private companies in the communication sector led to more awareness and usage of mobile and internet in the country (Table 2).

III. With the increase use of financial services through internet there has been increase in the number of companies which provide the platform to use these services (Figure 2).

IV. With the availability of Third party companies and easy reach of mobile operators the subscriptions have increased from all the tables.

\section{References}

1. TELECOM REGULATORY AUTHORITY OF INDIA.

2. RBI and Regulation of Digital Financial Services in India, 2012-2016.

3. Digital India Programme: Importance And Impact.

4. Market Study of Digital Financial Services in India -Summary Report.

5. Indian Mobile Subscriber Base Reaches 934.58 Million At the End of April 2017: COAI. 